\title{
The Melanin Biosynthesis Genes of Alternaria alternata Can Restore Pathogenicity of the Melanin- Deficient Mutants of Magnaporthe grisea
}

\author{
Chie Kawamura, ${ }^{1}$ Jouji Moriwaki, ${ }^{1}$ Norio Kimura, ${ }^{1}$ Yasunari Fujita, ${ }^{1}$ Shin-ichi Fuji, ${ }^{2}$ Tetsuji Hirano, ${ }^{2}$ \\ Shinzo Koizumi, ${ }^{3}$ and Takashi Tsuge ${ }^{1}$ \\ ${ }^{1}$ School of Agricultural Sciences, Nagoya University, Chikusa, Nagoya 464-01, Japan; ${ }^{2}$ Aichi-Ken Agricul- \\ tural Research Center, Nagakute-Cho, Aichi 480-11, Japan; ${ }^{3}$ Aichi-Ken Agricultural Research Center, \\ Mountainous Region Experiment Farm, Inabu-Cho, Aichi 441-25, Japan \\ Received 27 November 1996. Accepted 4 March 1997.
}

\begin{abstract}
The phytopathogenic fungi Magnaporthe grisea and Alternaria alternata produce melanin via the polyketide biosynthesis, and both fungi form melanized colonies. However, the site of melanin deposition and the role of melanin in pathogenicity differ between these two fungi. M. grisea accumulates melanin in appressoria, and their melanization is essential for host penetration. On the other hand, $A$. alternata produces colorless appressoria, and melanin is not relevant to host penetration. We examined whether the melanin biosynthesis genes of A. alternata could complement the melanin-deficient mutations of $M$. grisea. Melanin-deficient, nonpathogenic mutants of $M$. grisea, albino $\left(\mathrm{Alb}^{-}\right)$, rosy $\left(\mathrm{Rsy}^{-}\right)$, and buff $\left(\mathrm{Buf}^{-}\right)$, were successfully transformed with a cosmid clone pMBR1 that carries melanin biosynthesis genes $A L M, B R M 1$, and $B R M 2$ of $A$. alternata. This transformation restored the melanin synthesis of the $\mathrm{Alb}^{-}$and Buf' mutants, but not that of the Rsy $^{-}$mutant. The melanin-restored transformants regained mycelial melanization, appressorium melanization, and pathogenicity to rice. Further, transformation of $\mathrm{Alb}^{-}$ and Buf ${ }^{-}$mutants with subcloned $A L M$ and $B R M 2$ genes, respectively, also produced melanin-restored transformants. These results indicate that the Alternaria genes $A L M$ and $B R M 2$ can restore pathogenicity to the mutants $\mathrm{Alb}^{-}$and Buf ${ }^{-}$, respectively, due to their function during appressorium development in $M$. grisea.
\end{abstract}

Additional keywords: conidial melanization, conidiation, hostspecific toxin, the Japanese pear pathotype of A. alternata.

Many fungi produce a distinctive dark brown or black pigment, melanin, via polyketide biosynthesis, the last step of

Corresponding author: Takashi Tsuge

E-mail: ttsuge@nuagr1.agr.nagoya-u.ac.jp

Present address of J. Moriwaki: National Institute of Agro-Environmental Sciences, 3-1-1 Kannondai, Tsukuba 305, Japan.

Present address of N. Kimura: Takarazuka Research Center, Sumitomo Chemical Co. Ltd., Takatsukasa, Takarazuka 665, Japan.

Present address of Y. Fujita: Graduate School of Agriculture, Kyoto University, Kyoto 606, Japan. which is the polymerization of 1,8-dihydroxynaphthalene (DHN) (Fig. 1A) (Bell and Wheeler 1986). The biosynthetic pathway of DHN melanin was first characterized in Verticillium dahliae by using melanin-deficient mutants (Bell et al. 1976; Stipanovic and Bell 1976). In general, melanin accumulates in fungal cell walls and has been considered to confer tolerance to environmental stresses, such as UV radiation (Durrell 1964; Zhdanova and Pokhodenko 1974; Wang and Casadevall 1994), microbial lysis (Lockwood 1960; Bloomfield and Alexander 1967; Kuo and Alexander 1967; Hyakumachi et al. 1987), and defense responses of host plants and animals against fungal infection (Aver'Yanov et al. 1989; Dzhavakhiya et al. 1990; Jacobson et al. 1995).

The imperfect fungus Alternaria alternata is generally a ubiquitous saprophytic fungus. In addition, A. alternata contains seven phytopathogenic variants, designated pathotypes, that cause severe diseases on different plants by producing

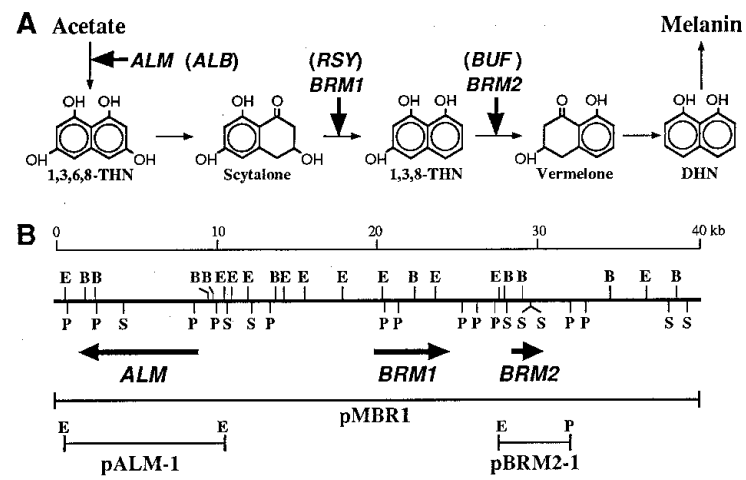

Fig. 1. Melanin biosynthetic pathway in filamentous fungi and the melanin biosynthesis gene cluster of Alternaria alternata. A, The steps controlled by the A. alternata genes $A L M, B R M 1$, and $B R M 2$ are denoted by thick arrows (Kimura and Tsuge 1993). Corresponding genes identified in Magnaporthe grisea are shown in parentheses (Chumley and Valent 1990). 1,3,6,8-THN = 1,3,6,8-tetrahydroxynaphthalene; $1,3,8$ - $\mathrm{THN}=1,3,8$-trihydroxynaphthalene; $\mathrm{DHN}=1,8$-dihydroxynaphthalene. B, Restriction endonuclease map of the $40-\mathrm{kb}$ region containing the $A L M, B R M 1$, and $B R M 2$ genes. Arrows indicate direction of transcription and maximum sizes of the gene transcription units (Kimura and Tsuge 1993). Cosmid pMBR1 and plasmids pALM-1 and pBRM2-1 were used for transformation of melanin-deficient mutants of $M$. grisea. B, BamHI; E, EcoRI; P, PstI; S, SalI. 
host-specific toxins (Nishimura and Kohmoto 1983; Kusaba and Tsuge 1995). A. alternata produces DHN melanin, which accumulates in the cell walls of conidia and hyphae (Wheeler 1983; Tanabe et al. 1995). We have previously reported the isolation of the gene cluster involved in melanin biosynthesis of the Japanese pear pathotype of A. alternata (Kimura and Tsuge 1993), which causes black spot of Japanese pear by producing host-specific AK-toxin (Tanaka 1933; Nakashima et al. 1985; Otani et al. 1985). A genomic cosmid library of a wild-type strain of this pathogen was screened for the presence of genes required for melanin biosynthesis by introducing DNA of the library into the albino $\left(\mathrm{Alm}^{-}\right)$, light brown $\left(\mathrm{Brm}^{-}\right)$, and brown $\left(\mathrm{Brm} 2^{-}\right)$mutants (Kimura and Tsuge 1993; Tanabe et al. 1995). A cosmid clone, named pMBR1, was found to restore melanin synthesis to all three mutants, and the genes complementing each of the three mutations were designated $A L M, B R M 1$, and $B R M 2$, respectively (Fig. 1B) (Kimura and Tsuge 1993). These genes are now considered to code for the enzymes controlling the respective steps in the melanin biosynthetic pathway shown in Figure 1 (Kimura and Tsuge 1993; Tanabe et al. 1995).

Chumley and Valent (1990) isolated three classes of melanin-deficient mutants of the rice blast pathogen $M$. grisea, albino $\left(\mathrm{Alb}^{-}\right)$, rosy $\left(\mathrm{Rsy}^{-}\right)$, and buff $\left(\mathrm{Buf}^{-}\right)$, and showed that the three mutant phenotypes are due to defects of single genes, designated $A L B, R S Y$, and $B U F$, at unlinked loci. Based on comparison of pigmentation phenotypes of mutants, $A L M$, $B R M 1$, and $B R M 2$ of A. alternata can be considered to have functions identical with those of $A L B, R S Y$, and $B U F$ of $M$. grisea, respectively, in melanin biosynthesis (Fig. 1A) (Chumley and Valent 1990; Kimura and Tsuge 1993).

Melanin-deficient mutants and the parent strain of the Japanese pear pathotype of A. alternata were found to develop approximately the same numbers of similar-size lesions on susceptible pear leaves in laboratory tests, indicating that the ability to produce melanin is probably not relevant to the pathogenicity of this pathogen (Tanabe et al. 1995). In contrast, melanin production is known to be an essential factor for pathogenicity in M. grisea (Woloshuk et al. 1980; Chumley and Valent 1990). Both M. grisea and A. alternata produce melanin during vegetative growth, resulting in melanized colonies, but the melanization sites and the roles of melanin seem to differ. The Alternaria spp. produce darkly melanized conidia, while the Magnaporthe conidia are colorless. Conidial melanization in A. alternata is considered to play an important role in longevity and survival of conidia in nature (Rotem 1994). On the other hand, appressoria, differentiated forms at the tips of germ tubes with a spherical or dome shape, of $M$. grisea are darkly melanized, while the Alternaria appressoria are colorless. Many pathogenic fungi penetrate host cells by elaborating infection hypha from appressoria (Staples and Hoch 1987; Mendgen and Deising 1993). Appressorium melanization of $M$. grisea is implicated as an essential step for the successful penetration of the host cell (Woloshuk et al. 1983; Howard and Ferrari 1989; Chumley and Valent 1990; Howard et al. 1991). Howard and Ferrari (1989) provided convincing evidence that DHN melanin mediates the buildup of hydrostatic pressure in the appressorium and that this high pressure provides the essential driving force for a mechanical penetration component. Similar roles of melanin have been reported in Colletotrichum lagenarium
(Kubo et al. 1982) and C. lindemuthianum (Wolkow et al. 1983). These facts suggest a diversity of roles for melanin and the regulation mechanisms of melanin biosynthesis genes in morphogenesis and pathogenicity among fungi.

We are interested in the similarity and diversity of the regulation mechanisms and roles of melanin genes in the morphogenesis, pathogenicity, and fitness among phytopathogenic fungi. In this study, we isolated three classes of melanin-deficient mutant of $M$. grisea and introduced the Alternaria melanin synthesis genes into the $M$. grisea mutants. The transformants were examined for melanin production during vegetative growth and morphogenesis, and also for pathogenicity, to determine whether the introduced melanin synthesis genes of A. alternata functionally displace the deficient genes of $M$. grisea.

\section{RESULTS}

\section{Homology of the melanin biosynthesis genes between $A$. alternata and $M$. grisea.}

Melanin biosynthetic pathways of A. alternata and $M$. grisea are considered to be identical (Woloshuk et al. 1980; Wheeler 1983; Chumley and Valent 1990; Tanabe et al. 1995). To deduce the nucleotide sequence homology in the melanin biosynthesis genes between A. alternata and $M$. grisea, DNA of $M$. grisea strains was hybridized with the A. alternata melanin genes. Southern blots of total cellular DNA from five strains of $M$. grisea, digested with EcoRI, were probed with the $A L M, B R M 1$, and BRM2 sequences of A. alternata. The wash of hybridized blots was conducted under relatively low stringency condition with $2 \times$ SSPE containing $0.1 \%$ sodium dodecyl sulfate at $50^{\circ} \mathrm{C}$. These probes did not hybridize (data not shown), suggesting that the degree of nucleotide sequence homology between melanin biosynthesis genes is relatively low for these two fungi.

\section{Isolation of melanin-deficient mutants of $M$. grisea .}

Conidia of M. grisea strain Ken60-19, which produces dark gray or black colonies due to melanin accumulation, were treated with $N$-methyl- $N$-nitro- $N$-nitrosoguanidine (MNNG). Three types of phenotypic mutants of this strain were selected, based on colony color on potato sucrose agar (PSA) medium: albino $\left(\mathrm{Alb}^{-}\right)$, rosy $\left(\mathrm{Rsy}^{-}\right)$, and buff $\left(\mathrm{Buf}^{-}\right)$. Three $\mathrm{Alb}^{-}$, one $\mathrm{Rsy}^{-}$, and three Buf ${ }^{-}$mutants were detected from about 1,200 colonies derived from MNNG-treated conidia. Among these seven mutants, three, designated MNK91-1 (Alb ${ }^{-}$, MNK91-2 $\left(\mathrm{Rsy}^{-}\right)$, and MNK91-3 (Buf $)$, were used in this study (Table 1). Appressoria of MNK91-1 and MNK91-2 were hyaline, and those of MNK91-3 were lightly pigmented (Table 1). The

Table 1. Melanin-deficient mutants of Magnaporthe grisea

\begin{tabular}{|c|c|c|c|c|}
\hline Strain & Phenotype $^{\text {a }}$ & $\begin{array}{c}\text { Mycelial } \\
\text { color }^{b}\end{array}$ & $\begin{array}{l}\text { Appressorium } \\
\text { pigmentation }^{c}\end{array}$ & Pathogenicity $^{\mathrm{d}}$ \\
\hline Ken60-19 & Wild type & Black & Dark & + \\
\hline MNK91-1 & $\mathrm{Alb}^{-}$ & Albino & Hyaline & - \\
\hline MNK91-2 & $\mathrm{Rsy}^{-}$ & Rosy & Hyaline & - \\
\hline MNK91-3 & Buf $^{-}$ & Buff & Light & - \\
\hline
\end{tabular}

${ }^{a}$ Phenotype nomenclature followed that of Chumley and Valent (1990).

b Mycelial color was observed on potato sucrose agar.

c Appressorium pigmentation was observed on Teflon membranes.

${ }^{\mathrm{d}}$ Pathogenicity was assayed by spray inoculation of conidial suspension on rice seedlings of compatible cultivar Aichi-Asahi. +, pathogenic; -, nonpathogenic. 
MNK91-1 and MNK91-2 were clearly distinguished, because MNK91-2 was verified to accumulate scytalone in the culture (about $40 \mu \mathrm{g} / \mathrm{ml}$ ).

The pathogenicity of these mutants was examined by spray inoculations of conidial suspensions on rice seedlings of compatible cultivar Aichi-Asahi. The parent strain caused many spreading lesions on leaves, but melanin-deficient mutants caused no lesions (Table 1). These results were consistent with the data reported previously (Woloshuk et al. 1980, 1983; Chumley and Valent 1990).

\section{Transformation of the Magnaporthe melanin-deficient mutants with the Alternaria melanin genes.}

The melanin-deficient mutants of $M$. grisea were transformed with the cosmid pMBR1 containing the A. alternata genes $A L M, B R M 1$, and $B R M 2$, to examine whether these $A$. alternata melanin genes could complement the melanindeficient mutations of $M$. grisea. The successful transformants were confirmed by hygromycin B resistance $\left(\mathrm{Hyg}^{\mathrm{r}}\right)$, and melanin restoration of these transformants was examined based on colony melanization on PSA plate. About 32 and $50 \%$ of $\mathrm{Hyg}^{\mathrm{r}}$ transformants from the $\mathrm{Alb}^{-}$mutant MNK91-1 and the Buf $^{-}$mutant MNK91-3, respectively, formed melanized colonies on PSA (Table 2). Colony melanization of the transformants tended to be delayed and slightly lighter than that of the wild-type strain. In contrast, none of $60 \mathrm{Hyg}^{\mathrm{r}}$ transformants of the $\mathrm{Rsy}^{-}$mutant MNK91-2 regained melanin production (Table 2). These results suggest that the A. alternata genes $A L M$ and BRM2 can complement the $M$. grisea alb and buf mutations, respectively, but that the BRMI gene cannot complement the rsy mutation.

Further, each ALM and BRM2 gene region in the Alternaria cosmid pMBR1 was subcloned into the transformation vector pSH75, and subclones, named pALM-1 and pBRM2-1, were introduced into $\mathrm{Alb}^{-}$and $\mathrm{Buf}^{-}$mutants of $M$. grisea, respectively. Among the $\mathrm{Hyg}^{\mathrm{r}}$ transformants, melanin-restored transformants appeared at frequency rates of 10.8 and $24.5 \%$ from $\mathrm{Alb}^{-}$and Buf ${ }^{-}$mutants, respectively (Table 2).

\section{Hybridization and expression analyses of the $A$. alternata melanin genes in $M$. grisea transformants.}

The melanin-restored transformants from $\mathrm{Alb}^{-}$and $\mathrm{Buf}^{-} \mathrm{mu}-$ tants with the A. alternata cosmid pMBR1 were designated TAR and TBR series, respectively. The integrations of the $A l$ ternaria genes into the chromosome of the transformants were confirmed by Southern blot analysis. Total DNA, extracted from

Table 2. Genetic complementation of the melanin-deficient mutations of Magnaporthe grisea with the melanin biosynthesis genes of Alternaria alternata

\begin{tabular}{|c|c|c|c|c|}
\hline \multirow[b]{2}{*}{ Strain } & \multirow{2}{*}{$\begin{array}{c}\text { Transforming } \\
\text { DNA }^{\mathrm{a}}\end{array}$} & \multicolumn{2}{|c|}{ Transformants (no.) $^{b}$} & \multirow{2}{*}{$\begin{array}{l}\mathrm{Mel}^{+} \text {trans- } \\
\text { formants }(\%)\end{array}$} \\
\hline & & $\mathrm{Mel}^{+}$ & $\mathrm{Mel}^{-}$ & \\
\hline MNK91-1 & pMBR1 & 13 & 28 & 31.7 \\
\hline$\left(\mathrm{Alb}^{-}\right)$ & pALM-1 & 4 & 33 & 10.8 \\
\hline $\begin{array}{l}\text { MNK91-2 } \\
\left(\mathrm{Rsy}^{-}\right)\end{array}$ & pMBR1 & 0 & 60 & 0.0 \\
\hline MNK91-3 & pMBR1 & 20 & 20 & 50.0 \\
\hline$\left(\mathrm{Buf}^{-}\right)$ & pBRM2-1 & 23 & 71 & 24.5 \\
\hline
\end{tabular}

\footnotetext{
a See Figure 1B.

${ }^{\mathrm{b}}$ Each value represents the number of $\mathrm{Mel}^{+}$(melanin-restored) and $\mathrm{Mel}^{-}$ (melanin-unrestored) transformants.
}

the parent strain Ken60-19, the $\mathrm{Alb}^{-}$mutant MNK91-1, and five TAR series transformants, was digested with EcoRI or SalI, and the blots were hybridized with the $A L M$ probe. The probe hybridized to DNA of all the melanin-restored transformants, but not to Ken60-19 or MNK91-1 DNA (Fig. 2A). TAR series transformants shared a 9.4-kb EcoRI fragment and a 6.2-kb SalI fragment, showing the presence of the full-length $A L M$ gene in the transformant genome. Total DNA, extracted from the strain Ken60-19, the Buf ${ }^{-}$mutant MNK91-3, and five TBR series transformants, was digested with EcoRI or PstI, and the blots were hybridized with the $B R M 2$ probe. The probe hybridized to DNA of all the transformants, but not to Ken60-19 and MNK913 DNA (Fig. 2B). An 8.5-kb EcoRI fragment and a 4.5-kb PstI fragment were detected from all TBR series transformants, and the presence of the full-length $B R M 2$ gene in the transformant genome was also identified.

Frequency of appearance of melanin-restored transformants from MNK91-1 or MNK91-3 was relatively low (Table 2). When MNK91-1 was transformed with pALM-1, only $10.8 \%$ of
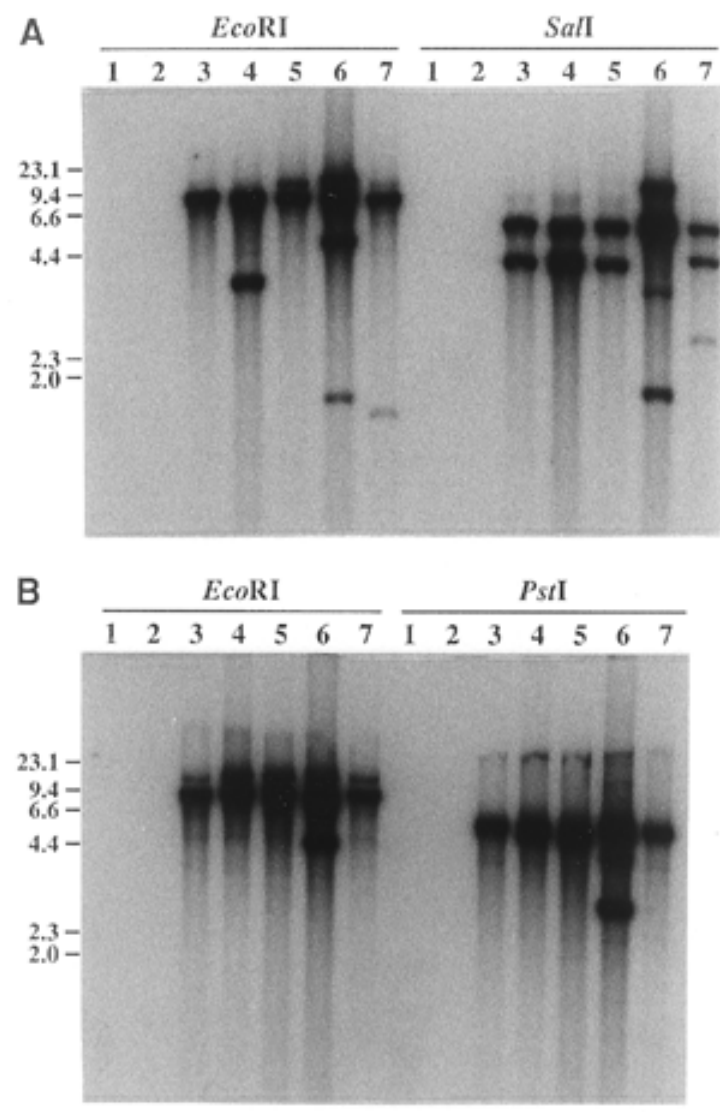

Fig. 2. Southern blot analysis of the melanin-restored transformants of Magnaporthe grisea. Total DNA ( $1 \mu \mathrm{g} / \mathrm{lane})$ was digested with a restriction enzyme, electrophoresed in $0.8 \%$ agarose gel, transferred to nylon membranes, and probed. A, DNA from wild-type strain Ken60-19 (lane 1), the Alm ${ }^{-}$mutant MNK91-1 (lane 2) and the melanin-restored transformants TAR-1 to TAR-5 (lanes 3 to 7) was probed with the 9.4-kb EcoRI fragment of pMBE1 containing the $A L M$ sequence. B, DNA from wild-type strain Ken60-19 (lane 1), the Brm2- mutant MNK91-3 (lane 2) and the melanin-restored transformants TBR-1 to TBR-5 (lanes 3 to 7) was probed with the 4.2-kb EcoRI-PstI fragment of pMBEP10 containing the $B R M 2$ sequence. The sizes (in kilobases) of marker DNA fragments (HindIII-digested $\lambda$ DNA) are indicated on the left. 
transformants restored the melanin production (Table 2). Southern blot analysis of integration manner of transforming DNA in the melanin-unrestored pALM-1 transformants indicated that most of these transformants did not contain the full length of the $A L M$ gene, probably resulting from double-strand breaks or recombination within the gene sequence during its integration into the recipient chromosomes (data not shown).

Expression of the Alternaria genes in the Magnaporthe melanin-restored transformants was confirmed by RNA blot analysis with total RNA from melanized mycelia of TAR-1, TAR-2, TBR-1, and TBR-2, grown on oatmeal sucrose agar. As a positive control, total RNA of A. alternata strain 15A was extracted from mycelia grown on the same plates. A single hybridizing band of about $7.2 \mathrm{~kb}$ was detected in total RNA from TAR-1, TAR-2, and $15 \mathrm{~A}$ with the $A L M$ probe (Fig. 3A). The BRM2 probe hybridized to a single band of about $0.9 \mathrm{~kb}$ in total RNA from TBR-1, TBR-2, and 15A (Fig. 3B). These transcript sizes were identical to those of $A L M$ and $B R M 2$ determined previously for A. alternata (Kimura and Tsuge 1993). The hybridization signals for the $M$. grisea transformants, however, were weaker than those for A. alternata RNA. The ALM transcript levels in TAR-1 and TAR-2 were less than $50 \%$ of that in $A$. alternata, and the BRM2 transcript levels in TBR-1 and TBR-2 were less than $30 \%$ of that in A. alternata. Total RNA of wildtype strain Ken60-19 of $M$. grisea did not contain any bands hybridized with these probes (data not shown).

\section{Morphogenesis and pathogenicity of $M$. grisea transformants.}

The morphogenesis and pathogenicity of each three transformants of TAR and TBR series were determined. Conidial suspensions of these transformants were placed on Teflon membranes to observe spore germination, appressorium formation, and appressorium pigmentation. TAR and TBR series transformants formed melanized appressoria, while the melanin-deficient mutants MNK91-1 and MNK91-3 formed hyaline and lightly pigmented appressoria, respectively (Fig. 4A). Appressorium melanization of transformants, however, was slightly lighter than that of the wild-type strain. There were no significant differences in spore germination and appressorium formation rates among the wild-type strain, melanin-deficient mutants, and melanin-restored transformants (data not shown). These results indicate that the A. alternata genes $A L M$ and $B R M 2$ are functional and can complement the deficiency of melanization during appressorium development as well as during vegetative growth in $M$. grisea.

Since the appressorium pigmentation in $M$. grisea is known to be essential for host penetration, pathogenicity of the melaninrestored transformants was examined by using both spray and drop inoculation of conidial suspensions. Conidial suspensions were sprayed on rice seedlings of compatible cultivar AichiAsahi. Melanin-deficient mutants did not cause any lesions on rice leaves, but melanin-restored TAR and TBR transformants caused many spreading lesions on leaves similar to wild-type strain (Fig. 4B). To confirm the origin of the lesion development, conidiation from the lesions caused by transformants was induced on $2 \%$ water agar, and the $\mathrm{Hyg}^{\mathrm{r}}$ and appressorium pigmentation of the resulting conidia were examined. All singleisolated conidia from the lesions grew well and formed melanized colonies on PSA containing hygromycin B. When conidia formed on a lesion were inoculated on Teflon membranes, they germinated, and pigmentation of appressoria was observed. These results confirm that the lesions were caused by the melanin-restored transformants.

When conidial suspensions were directly placed on wounded and unwounded leaves, melanin-deficient mutants caused lesions only on wounded leaves (Fig. 4C). In contrast, wild-type strain and the melanin-restored transformants caused lesions on unwounded leaves as well as wounded leaves (Fig. 4C). These results strongly suggest that the melanin-restored transformants regained penetration ability, subsequently with restoration of appressorium pigmentation due to the function of the transformed Alternaria genes. However, TAR and TBR tended to cause smaller-sized lesions than the wild-type strain.

\section{DISCUSSION}

Melanin acts as a pathogenicity factor in the rice blast fungus $M$. grisea. Melanin-deficient mutants or wild-type strain treated with a melanin biosynthesis inhibitor cannot penetrate the host plant (Woloshuk et al. 1980, 1983; Chumley and Valent 1990). The critical role of melanin is considered to be due to the differential permeability of the melanin layer to water and solute allowing high turgor pressure in the protoplasm to build up and force a specialized penetration peg through the outer plant surface into the plant tissue (Howard
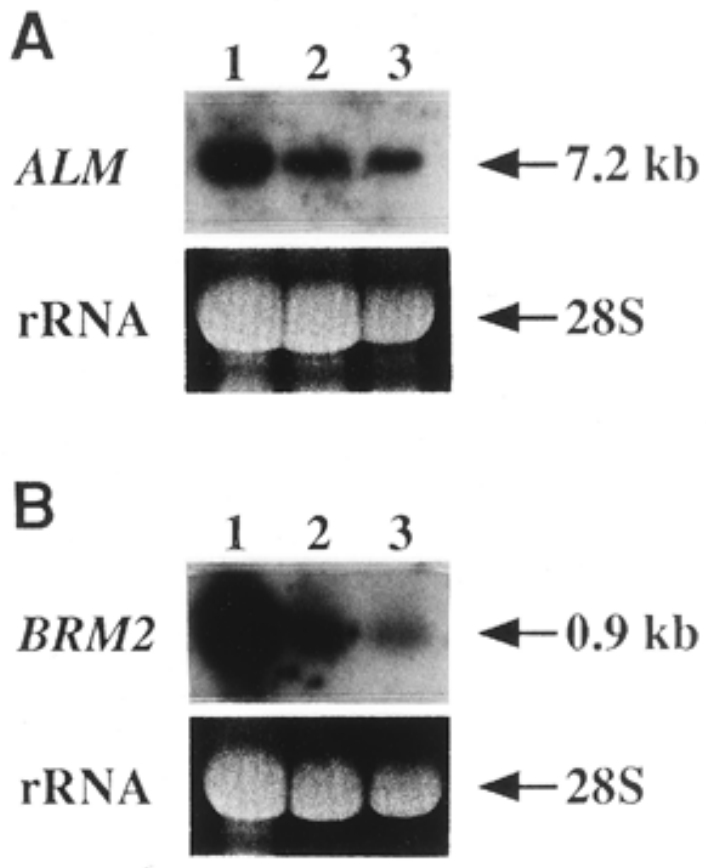

Fig. 3. Detection of mRNA of the Alternaria alternata genes in the melanin-restored transformants of Magnaporthe grisea. Total RNA (20 $\mu \mathrm{g} / \mathrm{lane})$ was electrophoresed in a $1.0 \%$ agarose gel containing $2.2 \mathrm{M}$ formaldehyde and $0.5 \mu \mathrm{g}$ of acridine orange per $\mathrm{ml}$, transferred to nylon membranes, and probed. A, Total RNA from A. alternata strain 15A (lane 1) and the $M$. grisea melanin-restored transformants TAR-1 and TAR-2 (lanes 2 and 3) was probed with the 9.4-kb EcoRI fragment of pMBE1 containing the ALM sequence. B, Total RNA from A. alternata strain $15 \mathrm{~A}$ (lane 1) and the $M$. grisea melanin-restored transformants TBR-1 and TBR-2 (lanes 2 and 3) was probed with the 4.2-kb EcoRI-PstI fragment of pMBEP10 containing the BRM2 sequence. The $28 \mathrm{~S}$ rRNA stained with acridine orange in the electrophoresed gel is also shown. 
and Ferrari 1989; Howard et al. 1991). In contrast, A. alternata produces colorless, tiny appressoria, and melanin is not directly involved in pathogenicity (Tanabe et al. 1995). Although both fungi produce melanin, resulting in melanized colony formation, the role and deposition sites of melanin seem to differ. This study attempted to analyze the similarities and the diversity in melanin biosynthesis, especially the functions of melanin genes, of $A$. alternata and M. grisea.

We first examined nucleotide homology of the melanin biosynthesis genes between these two fungi by Southern blot analysis with the Alternaria gene probes. The analysis could not detect the Alternaria gene homologues in DNA of $M$. grisea strains. However, similar analysis with several other fungal species detected the homologous DNA from Cochliobolus and Colletotrichum spp. (C. Kawamura, N. Kimura, and T. Tsuge, unpublished data), which are also known to produce DHN melanin (Bell and Wheeler 1986). Further comparisons of direct nucleotide sequences will probably clarify the phylogeny of the melanin biosynthesis genes among fungi.

\section{A}

1

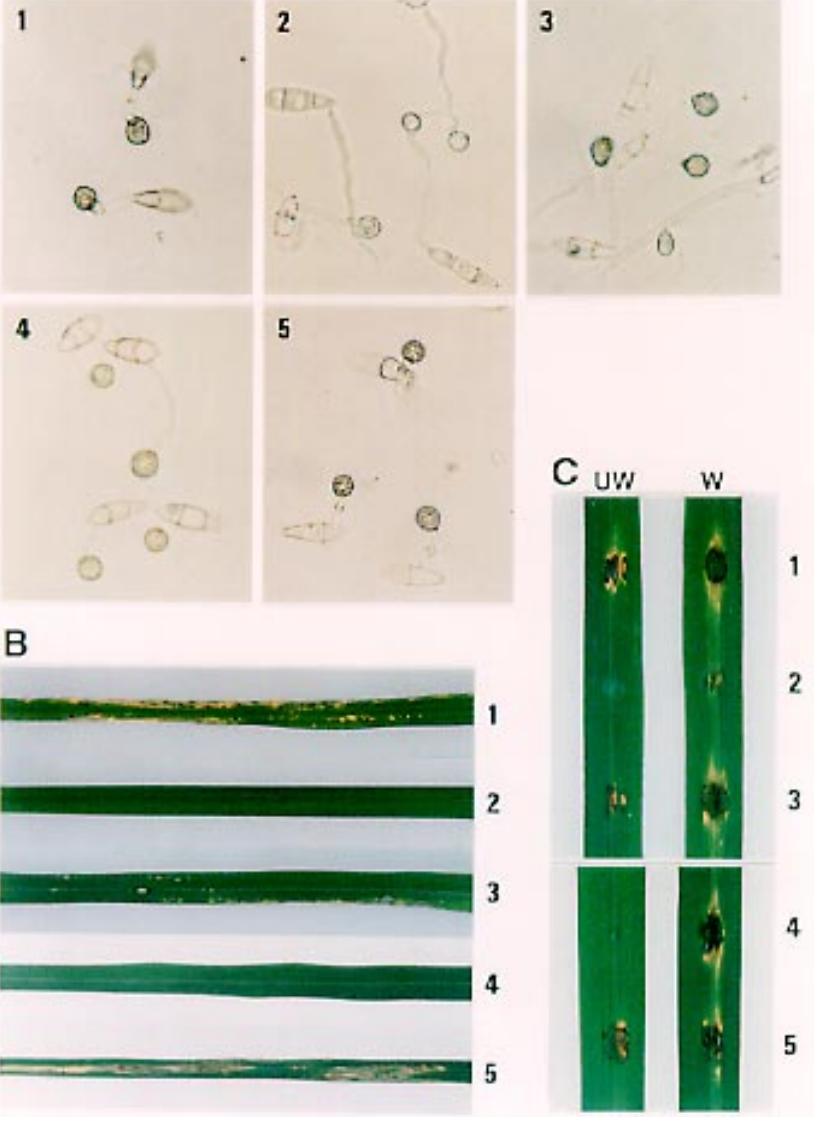

Fig. 4. Appressorium pigmentation and pathogenicity of the melaninrestored transformants of Magnaporthe grisea. 1, wild-type strain Ken60-19; 2, Alb ${ }^{-}$mutant MNK91-1; 3, melanin-restored transformant TAR-1 from MNK91-1; 4, Buf ${ }^{-}$mutant MNK91-3; 5, melanin-restored transformant TBR-1 from MNK91-3. A, Conidial suspensions were placed on Teflon membranes and incubated at $25^{\circ} \mathrm{C}$ for $20 \mathrm{~h}$. B, Conidial suspensions were sprayed onto five-leaf-stage rice seedlings of the compatible cultivar Aichi-Asahi. Plants were incubated at $25^{\circ} \mathrm{C}$ for 5 days. C, Conidial suspensions were placed on wounded (W) or unwounded (UW) leaves and incubated at $25^{\circ} \mathrm{C}$ for 4 days. Sixth leaves were detached from eight-leaf-stage seedling and used for inoculation.
Although Southern blot analysis could not detect the Alternaria gene homologues from $M$. grisea strains, the roles of the $A L M, B R M 1$, and BRM2 genes of A. alternata are considered to be the same as $A L B, R S Y$, and $B U F$ genes, respectively, of $M$. grisea (Chumley and Valent 1990; Kimura and Tsuge 1993; Tanabe et al. 1995). To compare the function of melanin biosynthesis genes in these two fungi, we introduced the A. alternata genes into the melanin-deficient mutants of $M$. grisea and characterized the phenotypes of the transformants in detail.

As the first step, we isolated three classes of melanindeficient mutants of $M$. grisea as recipients for transformation with the Alternaria genes. Based on pigmentation phenotypes of vegetatively growing colonies, these mutants were supposed to result from the mutations of $A L B, R S Y$, or $B U F$ genes reported by Chumley and Valent (1990). Pathogenicity assays of these mutants confirmed the previous reports that these mutations cause the loss of pathogenicity to the host plant, subsequent to the lack of appressorium pigmentation (Woloshuk et al. 1980, 1983; Chumley and Valent 1990).

As the next step, we transformed these Magnaporthe mutants with the Alternaria cosmid pMBR1 containing $A L M$, $B R M 1$, and $B R M 2$ genes, and evaluated melanin restoration of transformants based on colony pigmentation. The melanin restoration was frequently observed in the transformants from $\mathrm{Alb}^{-}$and $\mathrm{Buf}^{-}$mutants. These melanin-restored transformants carried full-length copies of respective genes in their genome; transcripts in vegetatively growing mycelia were also detected. Furthermore, melanin production of $\mathrm{Alb}^{-}$and $\mathrm{Buf}^{-}$ mutants was also restored by transformation with the ALM and $B R M 2$ subclones, respectively. These results indicate that the Alternaria genes $A L M$ and BRM2 can be expressed in $M$. grisea during vegetative growth, and that their functions in DHN melanin synthesis are identical to those of the Magnaporthe genes $A L B$ and $B U F$, respectively.

In contrast, no melanin-restored transformants were obtained from the $\mathrm{Rsy}^{-}$mutant. The $\mathrm{Rsy}^{-}$mutant used in this study accumulated scytalone, an intermediate of melanin biosynthesis, suggesting that this mutant lacks scytalone dehydratase activity to convert scytalone to 1,3,8-trihydroxynaphthalene (Bell et al. 1976; Chumley and Valent 1990). The $\mathrm{Brm}^{-}$mutants of $A$. alternata, which were induced by both MNNG mutagenesis and transformation-mediated gene targeting, also accumulated scytalone in their cultures (Shiotani and Tsuge 1995; Tanabe et al. 1995). These facts suggest that two genes are involved in the step to convert scytalone to 1,3,8-trihydroxynaphthalene. The cDNA (740 bases) encoding scytalone dehydratase of $M$. grisea was sequenced and verified to encode the full-length (172 amino acids) scytalone dehydratase protein (Lundqvist et al. 1993). However, we detected a BRMI transcript of about $4.0 \mathrm{~kb}$ (Kimura and Tsuge 1993), indicating that the sizes of the RSY and BRMI transcripts are significantly different. The structure and function of these two genes might differ, and remain to be clarified.

The sites of melanin deposition in $M$. grisea and A. alternata are different. Conidia of $M$. grisea are colorless, and their appressoria are darkly melanized. On the other hand, the $A l$ ternaria spp. produce darkly melanized conidia, but their appressoria are colorless. Thus, we had much interest in whether the Alternaria genes can restore appressorium melanization in the M. grisea transformants. Our data presented here show that the melanin-restored transformants produced melanized 
appressoria like wild-type strains. More interestingly, all these transformants regained the ability to penetrate rice leaves of a compatible cultivar. These results strongly suggest that the Alternaria genes can be functional for appressorium melanization and also for restoration of pathogenicity in $M$. grisea. Recently, Takano et al. (1996) reported that the A. alternata $A L M$ gene also complemented the albino pks1 mutation of $C$. lagenarium. The Colletotrichum PKS1 gene and the Alternaria $A L M$ gene are both involved in polyketide synthesis in the melanin biosynthetic pathway (Kubo et al. 1991; Kimura and Tsuge 1993; Takano et al. 1995; Tanabe et al. 1995). The ALM gene transformants of $C$. lagenarium $\mathrm{Pks}^{-}$mutant regained mycelial melanization, appressorium melanization, and pathogenicity (Takano et al. 1996). This result also confirms the potential ability of the Alternaria melanin genes to substitute for the melanin genes of other fungal species.

Expression of the melanin biosynthesis genes of other fungi in A. alternata should also be determined. Recently, several melanin synthesis genes have been isolated from $M$. grisea and $C$. lagenarium: putative $R S Y$ and $B U F$ genes of $M$. grisea (Lundqvist et al. 1993; Vidal-Cros et al. 1994) and PKS1, SCD1, and THR1 genes of C. lagenarium (Takano et al. 1995; Kubo et al. 1996a; Perpetua et al. 1996). A. alternata produces darkly melanized conidia, while conidia of both $M$. grisea and C. lagenarium are colorless. Indeed, melanin-deficient mutations in A. alternata were found to induce less conidiation (Y. Fujita, C. Kawamura, and T. Tsuge, unpublished data). Thus, it will be important to observe not only mycelial melanization but also conidial melanization of A. alternata transformants with the Magnaporthe or Colletotrichum genes in future.

The linkage relationships of the melanin biosynthesis genes also vary among these fungi. Although the A. alternata genes $A L M, B R M 1$, and $B R M 2$ reside within an approximately $30-\mathrm{kb}$ region in the fungal chromosome (Kimura and Tsuge 1993), the $M$. grisea genes $A L B, R S Y$, and $B U F$ are unlinked (Chumley and Valent 1990). Kubo et al. (1996b) reported that the $C$. lagenarium genes $P K S 1, S C D 1$, and THRl apparently are not closely linked. Such differences in linkage relationships of the melanin biosynthesis genes among these fungi suggest the complex processes of acquisition and establishment of melanin biosynthesis in fungi.

We are now analyzing the period and site of expression of the melanin biosynthesis genes in A. alternata during the infection process. The promoter region of the Alternaria melanin genes will be also analyzed by using the reporter gene constructs fused with the melanin gene promoter to observe the promoter activity in situ. To study molecular evolution of melanin biosynthesis in fungi, future work will be directed at identification and comparison of the cis-acting elements of the melanin genes among fungi and at detection of the transacting regulators. Recently, some genes involved in infection have been cloned from M. grisea (Talbot et al. 1993; Sweigard et al. 1995; Dean et al. 1996). Among them, the MPG1 gene encoding a fungal hydrophobin was characterized as having an important role in appressorium formation (Talbot et al. 1993; 1996). Lau and Hamer (1996) definitively identified two genes, designated $N P R 1$ and $N P R 2$, encoding putative trans-acting regulators that induce $M P G 1$ expression during appressorium development. The relationship between these genes and melanin synthesis genes during infection-related differentiation will be another important study in future.

\section{MATERIALS AND METHODS}

\section{Fungal strains.}

The rice-infecting strains of $M$. grisea, Ken60-19 (race 037), Ina83R-25A (race 037), Ina85-182 (race 003), Ina91-02 (race 001), and TH68-126 (race 033), were used in Southern blot analysis. Strain Ken60-19 was used as the parent strain for isolation of melanin-deficient mutants. Fungi were maintained on PSA.

\section{Conidiation.}

Fungi were grown on oatmeal sucrose agar (5\% oatmeal, $1.5 \%$ sucrose, $1.5 \%$ agar) plates at $25^{\circ} \mathrm{C}$ for 14 days, followed by placing the plates under BLB lamps (FL20S, 20W, Toshiba, Osaka, Japan) for 4 days after removing the aerial mycelia with a sterilized brush (Xiao et al. 1994). Conidia formed were brushed off, suspended in sterilized water, and used for experiments.

\section{Isolation of the $M$. grisea mutants.}

Melanin-deficient mutants were isolated by mutagenesis of conidia of strain Ken60-19 with MNNG. Conidia were suspended in $40 \mu \mathrm{M}$ MNNG and incubated at $25^{\circ} \mathrm{C}$ for $4 \mathrm{~h}$ with shaking (70 rpm; Bio-Shaker BR-30LF, Taitec, Saitama, Japan). Under these conditions, about $5 \%$ of conidia survived. The treated conidia were collected by centrifugation at $700 \times$ $g$ for $5 \mathrm{~min}$ and plated on PSA. After incubation at $25^{\circ} \mathrm{C}$ for 2 to 3 days, growing colonies were transferred to a new PSA, and then their mycelial pigmentation was observed. Scytalone, an intermediate in the direct pathway to melanin, was extracted from the mutant culture on PSA by the method of Bell et al. (1976) and analyzed by high-performance liquid chromatography as described previously (Tanabe et al. 1995). Genetic and phenotypic nomenclature of $M$. grisea is that of Chumley and Valent (1990).

\section{Bacterial strains, cosmids, and plasmids.}

Escherichia coli HB101 and AG1 were used for cloning and propagation of plasmids and cosmids, respectively.

A cosmid clone pMBR1 was used for transformation of the melanin-deficient mutants of $M$. grisea (Fig. 1B). pMBR1 has been isolated from a cosmid library of the wild-type strain $15 \mathrm{~A}$ of the Japanese pear pathotype of A. alternata (Kimura and Tsuge 1993). It carries an approximately 40-kb fragment of the fungal genomic DNA in which three genes, $A L M$, $B R M 1$, and $B R M 2$, involved in melanin biosynthesis are located (Fig. 1B) (Kimura and Tsuge 1993).

Subclones pMBE1, pMBE8, and pMBEP10, containing $A L M, B R M 1$, and $B R M 2$ sequences, respectively, were used as hybridization probes (Kimura and Tsuge 1993). The 9.4$\mathrm{kb}$ EcoRI insert of pMBE1 and the 4.2-kb EcoRI-PstI insert of pMBEP10 were purified by electroelution and blunted with T4 DNA polymerase. Each of these fragments was introduced into the EcoRV site of fungal integrative transformation vector pSH75 to make pALM-1 and pBRM2-1 (Fig. 1B) (Kimura and Tsuge 1993). The plasmid pSH75 carries the hph (hygromycin B phosphotransferase) gene as a selectable marker (Gritz and Davies 1983; Cullen et al. 1987; Kimura and Tsuge 1993). In pALM-1 and pBRM2-1, transcriptional directions of the melanin genes are the same as that of the $h p h$ gene. 


\section{Fungal transformation.}

Protoplasts of $M$. grisea were prepared as described by Parsons et al. (1987), with an enzyme solution containing $10 \mathrm{mg}$ of Novozym 234 (Novo Nordisk, Bagsvaerd, Denmark) per $\mathrm{ml}$ in $1 \mathrm{M}$ sorbitol. Protoplasts were suspended in STC (1.2 M sorbitol, $25 \mathrm{mM}$ Tris- $\mathrm{HCl}, \mathrm{pH} 7.5,25 \mathrm{mM} \mathrm{CaCl}_{2}$ ) at $3 \times 10^{8}$ per $\mathrm{ml}$, and 200- $\mu \mathrm{l}$ portions were treated with cosmid DNA $(25 \mu \mathrm{g})$ or plasmid DNA (10 $\mu \mathrm{g})$ according to the method of Leung et al. (1990). Following transformation, the protoplasts were collected by centrifugation at $950 \times g$ for $5 \mathrm{~min}$. The pellet was suspended in $5 \mathrm{ml}$ of complete medium (CM) (Leung et al. 1990) containing 1.2 M sorbitol and plated directly onto regeneration agar medium $(\mathrm{CM}$ containing $1.2 \mathrm{M}$ sorbitol and $2 \%$ agar). Plates were incubated at $25^{\circ} \mathrm{C}$ for 3 days and then overlaid with regeneration agar medium containing $150 \mu \mathrm{g}$ of hygromycin B (Wako Pure Chemicals, Osaka, Japan) per ml. Colonies that grew out of the overlay were transferred to PSA containing $150 \mu \mathrm{g}$ of hygromycin B per ml. Mycelial pigmentation was observed after incubation at $25^{\circ} \mathrm{C}$ for 7 days.

\section{Assays for infection-related morphogenesis and pathogenicity.}

For observation of conidial germination and appressorium formation, droplets $(10 \mu \mathrm{l})$ of conidial suspension $\left(10^{4} \mathrm{con}\right.$ $\mathrm{idia} / \mathrm{ml}$ ) were placed on Teflon membranes (Flonchemical, Osaka, Japan) and left in a humid chamber at $25^{\circ} \mathrm{C}$ for $20 \mathrm{~h}$. The frequencies of germination and appressorium formation were determined by counting at least 600 conidia, and the appressorium pigmentation was observed.

Pathogenicity assays were carried out with rice seedlings of cultivar Aichi-Asahi, which is compatible to strain Ken60-19. Two methods, spray inoculation and drop inoculation, were employed for pathogenicity assays. For spray inoculation, five-leaf-stage seedlings were used. Pots containing 10 rice seedlings were each sprayed with $3 \mathrm{ml}$ of a conidial suspension $\left(10^{5}\right.$ conidia $\left./ \mathrm{ml}\right)$ supplemented with $0.01 \%$ Tween 20 . After incubation at $25^{\circ} \mathrm{C}$ for 5 days, lesions on leaves were observed. Tissues of the leaves infected with transformants were excised and placed on $2 \%$ water agar to induce conidiation. The infecting pathogen was reisolated by single-conidial isolation from infected lesions and assayed for $\mathrm{Hyg}^{\mathrm{r}}$ on PSA plates containing $150 \mu \mathrm{g}$ of hygromycin B per ml and appressorium pigmentation on Teflon membrane.

For drop inoculation, sixth leaves were detached from eight-leaf-stage seedlings and used. Conidial suspension (20 $\mu \mathrm{l}, 10^{5}$ conidia $/ \mathrm{ml}$ ) was placed on the underside of leaves. Inoculation was also done on the wounded leaves. Detached leaves were wounded slightly by picking the surface of leaves, and conidial suspension was placed on the picked portion. Inoculated leaves were incubated in a humid chamber at $25^{\circ} \mathrm{C}$ for 4 days, and lesion development was observed.

\section{Nucleic acid extraction.}

For extraction of DNA, fungi were grown in $50 \mathrm{ml}$ of potato sucrose broth in $100-\mathrm{ml}$ Erlenmeyer flasks at $25^{\circ} \mathrm{C}$ for 3 days on an orbital shaker (120 rpm; Bio-Shaker BR-30LF, Taitec, Saitama, Japan). The resulting mycelia were ground in liquid nitrogen in a mortar with a pestle. Total cellular DNA was prepared from the powdered mycelia as described previously (Adachi et al. 1993).
For extraction of RNA, fungi were grown on oatmeal sucrose agar at $25^{\circ} \mathrm{C}$ for 5 days. The resulting colony was recovered and ground in liquid nitrogen in a mortar with a pestle. Total cellular RNA was extracted from the powdered mycelia as described by Timberlake (1986).

Plasmid DNA and cosmid DNA were isolated from E. coli cells by the alkaline lysis method (Sambrook et al. 1989).

\section{Nucleic acid hybridization.}

Restriction enzyme digestion of DNA and fractionation in agarose gels were performed by standard methods (Sambrook et al. 1989). RNA was electrophoretically fractionated in formaldehyde-agarose gels (Sambrook et al. 1989). Fractionated DNA and RNA were transferred to Hybond $\mathrm{N}^{+}$nylon membranes (Amersham, Arlington Heights, IL) and subjected to hybridization according to the manufacturer's recommendations. To detect genomic DNA of $M$. grisea homologous to the A. alternata melanin genes, hybridized blots were washed in $2 \times \operatorname{SSPE}\left(1 \times \mathrm{SSPE}\right.$ is $0.18 \mathrm{M} \mathrm{NaCl}, 10 \mathrm{mM} \mathrm{NaH} \mathrm{PO}_{4}[\mathrm{pH}$ 7.7], and $1 \mathrm{mM}$ EDTA) plus $0.1 \%$ sodium dodecyl sulfate at $50^{\circ} \mathrm{C}$. In other cases, hybridized blots were washed at $65^{\circ} \mathrm{C}$; the final wash was done in $0.1 \times \mathrm{SSPE}$ plus $0.1 \%$ sodium dodecyl sulfate.

DNA probes were labeled with $\left[\alpha_{-}{ }^{32} \mathrm{P}\right] \mathrm{dCTP}$ (ICN Biochemicals, Costa Mesa, CA) by the random-primer method (Feinberg and Vogelstein 1983).

\section{ACKNOWLEDGMENTS}

We are grateful to Kazuya Akimitsu for critical review of the manuscript. We thank Noriyuki Doke, Kazuhito Kawakita, and Hirofumi Yoshioka for valuable suggestions and discussions. We thank the Radioisotope Research Center, Nagoya University, for technical assistance. This work was supported by research grants from the Ministry of Education, Science and Culture of Japan.

\section{LITERATURE CITED}

Adachi, Y., Watanabe, H., Tanabe, K., Doke, N., Nishimura, S., and Tsuge, T. 1993. Nuclear ribosomal DNA as a probe for genetic variability in the Japanese pear pathotype of Alternaria alternata. Appl. Environ. Microbiol. 59:3197-3205.

Aver'Yanov, A. A., Lapikova, V. P., Petelina, G. G., and Dzhavakhiya, V. G. 1989. Increased sensitivity of pigment mutants of Pyricularia oryzae to toxic excretions of rice leaves. Fiziol. Rast. (Sofia) 36:1088-1095.

Bell, A. A., Puhalla, J. E., Tolmsoff, W. J., and Stipanovic, R. D. 1976. Use of mutants to establish (+)-scytalone as an intermediate in melanin biosynthesis by Verticillium dahliae. Can. J. Microbiol. 22:787-799.

Bell, A. A., and Wheeler, M. H. 1986. Biosynthesis and functions of fungal melanins. Annu. Rev. Phytopathol. 24:411-451.

Bloomfield, B. J., and Alexander, M. 1967. Melanins and resistance of fungi to lysis. J. Bacteriol. 93:1276-1280.

Chumley, F. G., and Valent, B. 1990. Genetic analysis of melanindeficient, nonpathogenic mutants of Magnaporthe grisea. Mol. PlantMicrobe Interact. 3:135-143.

Cullen, D., Leong, S. A., Wilson, L. J., and Henner, D. J. 1987. Transformation of Aspergillus nidulans with the hygromycin-resistance gene, $h p h$. Gene 57:21-26.

Dean, R. A., Blackmon, B. P., Brooks, J. C., Gilbert, R. D., Liu, S., Mitchell, T. K., Shieh, M.-T., and Zhu, H. 1996. Cell surface communication in appressorium development by Magnaporthe grisea. Pages 59-71 in: Molecular Aspects of Pathogenicity and Host Resistance: Requirement for Signal Transduction. D. Mills, H. Kunoh, N. T. Keen, and S. Mayama, eds. American Phytopathological Society, St. Paul, MN.

Durrell, L. W. 1964. The composition and structure of walls of dark fungus spores. Mycopathol. Mycol. Appl. 23:339-345. 
Dzhavakhiya, V. G., Aver'Yanov, A. A., Minaev, V. I., Ermolinskii, B. S., Voinova, T. M., Lapikova, V. P., Petelina, G. G., and Vavilova, N. A. 1990. Structure and function of cell wall melanin of the micromycete Pyricularia oryzae Cav. the rice blast pathogen. Zh. Obshch. Biol. 51:528-535.

Feinberg, A. P., and Vogelstein, B. 1983. A technique for radiolabelling DNA restriction endonuclease fragments to high specific activity. Anal. Biochem. 136:6-13.

Gritz, L., and Davies, J. 1983. Plasmid-encoded hygromycin B resistance: The sequence of hygromycin B phosphotransferase gene and its expression in Escherichia coli and Saccharomyces cerevisiae. Gene 25:179-188.

Howard, R. J., and Ferrari, M. A. 1989. Role of melanin in appressorium function. Exp. Mycol. 13:403-418.

Howard, R. J., Ferrari, M. A., Roach, D. H., and Money, N. P. 1991 Penetration of hard substrates by a fungus employing enormous turgor pressures. Proc. Natl. Acad. Sci. USA 88:11281-11284.

Hyakumachi, M., Yokoyama, K., and Ui, T. 1987. Role of melanin in susceptibility and resistance of Rhizoctonia solani to microbial lysis. Trans. Br. Mycol. Soc. 89:27-33.

Jacobson, E. S., Hove, E., and Emery, H. S. 1995. Antioxidant function of melanin in black fungi. Infect. Immun. 63:4944-4945.

Kimura, N., and Tsuge, T. 1993. Gene cluster involved in melanin biosynthesis of the filamentous fungus Alternaria alternata. J. Bacteriol. 175:4427-4435.

Kubo, Y., Nakamura, H., Kobayashi, K., Okuno, T., and Furusawa, I. 1991. Cloning of a melanin biosynthetic gene essential for appressorial penetration of Colletotrichum lagenarium. Mol. Plant-Microbe Interact. 4:440-445.

Kubo, Y., Suzuki, K., Furusawa, I., Ishida, N., and Yamamoto, M. 1982. Relation of appressorium pigmentation and penetration of nitrocellulose membranes by Colletotrichum lagenarium. Phytopathology 72: 498-501.

Kubo, Y., Takano, Y., Endo, N., Yasuda, N., Tajima, S., and Furusawa, I. 1996a. Cloning and structural analysis of the melanin biosynthesis gene SCD1 encoding scytalone dehydratase in Colletotrichum lagenarium. Appl. Environ. Microbiol. 62:4340-4344.

Kubo, Y., Takano, Y., and Furusawa, I. 1996b. Molecular genetic analysis of melanin biosynthetic genes essential for appressorium function in Colletotrichum lagenarium. Pages 73-82 in: Molecular Aspects of Pathogenicity and Host Resistance: Requirement for Signal Transduction. D. Mills, H. Kunoh, N. T. Keen, and S. Mayama, eds. American Phytopathological Society, St. Paul, MN.

Kuo, M. J., and Alexander, M. 1967. Inhibition of the lysis of fungi by melanins. J. Bacteriol. 94:624-629.

Kusaba, M., and Tsuge, T. 1995. Phylogeny of Alternaria fungi known to produce host-specific toxins on the basis of variation in internal transcribed spacers of ribosomal DNA. Curr. Genet. 28:491-498.

Lau, G., and Hamer, J. E. 1996. Regulatory genes controlling MPG1 expression and pathogenicity in the rice blast fungus Magnaporthe grisea. Plant Cell 8:771-781.

Leung, H., Lehtinen, U., Karjalainen, R., Skinner, D., Tooley, P., Leong, S., and Ellingboe, A. 1990. Transformation of the rice blast fungus Magnaporthe grisea to hygromycin B resistance. Curr. Genet. 17:409-411.

Lockwood, J. L. 1960. Lysis of mycelium of plant-pathogenic fungi by natural soil. Phytopathology 50:787-789.

Lundqvist, T., Weber, P. C., Hodge, C. N., Braswell, E. H., Rice, J., and Pierce, J. 1993. Preliminary crystallographic studies on scytalone dehydratase from Magnaporthe grisea. J. Mol. Biol. 232:999-1002.

Mendgen, K., and Deising, H. 1993. Infection structures of fungal plant pathogens - a cytological and physiological evaluation. New Phytol. 124:193-213

Nakashima, T., Ueno, T., Fukami, H., Taga, T., Masuda, H., Osaki, K., Otani, H., Kohmoto, K., and Nishimura, S. 1985. Isolation and structures of AK-toxin I and II, host-specific phytotoxic metabolites produced by Alternaria alternata Japanese pear pathotype. Agric. Biol. Chem. 49:807-815.

Nishimura, S., and Kohmoto, K. 1983. Host-specific toxins and chemical structures from Alternaria species. Annu. Rev. Phytopathol. 21: 87-116.

Otani, H., Kohmoto, K., Nishimura, S., Nakashima, T., Ueno, T., and Fukami, H. 1985. Biological activities of AK-toxins I and II, hostspecific toxins from Alternaria alternata Japanese pear pathotype. Ann. Phytopathol. Soc. Jpn. 51:285-293.

Parsons, K. A., Chumley, F. G., and Valent, B. 1987. Genetic transfor- mation of the fungal pathogen responsible for rice blast disease. Proc. Natl. Acad. Sci. USA 84:4161-4165.

Perpetua, N. S., Kubo, Y., Yasuda, N., Takano, Y., and Furusawa, I. 1996. Cloning and characterization of a melanin biosynthetic THRI reductase gene essential for appressorial penetration of Colletotrichum lagenarium. Mol. Plant-Microbe Interact. 9:323-329.

Rotem, J. 1994. The Genus Alternaria: Biology, Epidemiology, and Pathogenicity. American Phytopathological Society, St. Paul, MN.

Sambrook, J., Fritsch, E. F., and Maniatis, T. A. 1989. Molecular Cloning: A Laboratory Manual. 2nd ed. Cold Spring Harbor Laboratory, Cold Spring Harbor, NY.

Shiotani, H., and Tsuge, T. 1995. Efficient gene targeting in the filamentous fungus Alternaria alternata. Mol. Gen. Genet. 248:142-150.

Staples, R. C., and Hoch, H. C. 1987. Infection structure - form and function. Exp. Mycol. 11:163-169.

Stipanovic, R. D., and Bell, A. A. 1976. Pentaketide metabolites of Verticillium dahliae. 3. Identification of (-)-3,4-dihydro-3,8-dihydroxy$1(2 H)$-naphthalenone [(-)-vermelone] as a precursor to melanin. J. Org. Chem. 41:2468-2469.

Sweigard, J. A., Carroll, A. M., Kang, S., Farrall, L., Chumley, F. G., and Valent, B. 1995. Identification, cloning, and characterization of $P W L 2$, a gene for host species specificity in the rice blast fungus. Plant Cell 7:1221-1233.

Takano, Y., Kubo, Y., Kawamura, C., Tsuge, T., and Furusawa, I. 1996. Complementation of an albino mutant $\left(\mathrm{Pks}^{-}\right)$of Colletotrichum lagenarium with Alternaria alternata $A L M$ gene involved in melanin biosynthesis. (Abstr.) (In Japanese.) Ann. Phytopathol. Soc. Jpn. 61:617.

Takano, Y., Kubo, Y., Shimizu, K., Mise, K., Okuno, T., and Furusawa, I. 1995. Structural analysis of $P K S 1$, a polyketide synthase gene involved in melanin biosynthesis in Colletotrichum lagenarium. Mol. Gen. Genet. 249:162-167.

Talbot, N. J., Ebbole, D. J., and Hamer, J. E. 1993. Identification and characterization of $M P G 1$, a gene involved in pathogenicity from the rice blast fungus Magnaporthe grisea. Plant Cell 5:1575-1590.

Talbot, N. J., Kershaw, M. J., Wakley, G. E., de Vries, O. M. H., Wessels, J. G. H., and Hamer, J. E. 1996. MPGl encodes a fungal hydrophobin involved in surface interactions during infection-related development of Magnaporthe grisea. Plant Cell 8:985-999.

Tanabe, K., Park, P., Tsuge, T., Kohmoto, K., and Nishimura, S. 1995. Characterization of the mutants of Alternaria alternata Japanese pear pathotype deficient in melanin production and their pathogenicity. Ann. Phytopathol. Soc. Jpn. 61:27-33.

Tanaka, S. 1933. Studies on black spot disease of the Japanese pear (Pyrus serotina Rehd.). Mem. Coll. Agric. Kyoto Imp. Univ. 28:1-31.

Timberlake, W. E. 1986. Isolation of stage- and cell-specific genes from fungi. Pages 343-357 in: Biology and Molecular Biology of PlantPathogen Interactions. NATO ASI Ser., Vol. H1. J. A. Bailey, ed. Springer-Verlag, Berlin.

Vidal-Cros, A., Viviani, F., Labesse, G., Boccara, M., and Gaudry, M. 1994. Polyhydroxy-naphthalene reductase involved in melanin biosynthesis in Magnaporthe grisea: Purification, cDNA cloning and sequencing. Eur. J. Biochem. 219:985-992.

Wang, Y., and Casadevall, A. 1994. Decreased susceptibility of melanized Cryptococcus neoformans to UV light. Appl. Environ. Microbiol. 60:3864-3866

Wheeler, M. H. 1983. Comparisons of fungal melanin biosynthesis in ascomycetous, imperfect and basidiomycetous fungi. Trans. Br. Mycol. Soc. 81:29-36.

Wolkow, P. M., Sisler, H. D., and Vigil, E. L. 1983. Effect of inhibitors of melanin biosynthesis on structure and function of appressoria of Colletotrichum lindemuthianum. Physiol. Plant Pathol. 22:55-71.

Woloshuk, C. P., Sisler, H. D., Tokousbalides, C. M., and Dutky, S. R. 1980. Melanin biosynthesis in Pyricularia oryzae: Site of tricyclazole inhibition and pathogenicity of melanin-deficient mutants. Pestic. Biochem. Physiol. 14:256-264.

Woloshuk, C. P., Sisler, H. D., and Vigil, E. L. 1983. Action of the antipenetrant, tricyclazole, on appressoria of Pyricularia oryzae. Physiol. Plant Pathol. 22:245-259.

Xiao, J.-Z., Ohshima, A., Kamakura, T., Ishiyama, T., and Yamaguchi, I. 1994. Extracellular glycoprotein(s) associated with cellular differentiation in Magnaporthe grisea. Mol. Plant-Microbe Interact. 7:639-644.

Zhdanova, N. N., and Pokhodenko, V. D. 1974. The protective properties of fungal melanin pigment of some soil Dematiaceae. Radiat. Res. $59: 221$ 